\title{
The Future of Community Service-Learning in Canada
}

\author{
Geri Briggs
}

ABSTRACT Anchored by the question of what is needed for community service-learning (CSL) to continue to grow in Canada, this paper proposes three principles for effective campus-community engagement (CCE): 1) communities need to feel ownership of community-campus partnerships; 2) post-secondary institutions need to make the route to engagement clearer and easier to navigate for their communities; and 3) post-secondary institutions need to ensure infrastructure to support students, staff, faculty, and community involved in CCE. Aspiring toward better futures for CSL in this country, the author offers possible solutions for and approaches to CCE based on her observations, reflections, knowledge, and experience as former Director of the Canadian Alliance for Community Service-Learning (CACSL).

KEYWORDS community service-learning; campus-community engagement; recommendations for CSL; CACSL

In January 2010, I became the Director of the Canadian Alliance for Community ServiceLearning (CACSL). Six years of learning, exploration, discovery, joy, and frustration followed. Below, I share my perspectives on the future of community service-learning (CSL) in Canada based on observations, conversations, and reflections. ${ }^{1}$ My meditation revolves around the following question: what is needed for community service-learning to continue to grow and develop in Canada?

Let's begin with a quick history of CACSL. ${ }^{2}$ The tale of CACSL's creation is one of creativity, collaboration, and community building, which was initiated in 2001 when Marla Gaudet (then Program Manager of the Service Learning Program at St. Francis Xavier University) invited others she knew were practicing CSL in Canada to the first pan-Canadian CSL Symposium. Approximately ten people were in attendance (Fryer et al., 2007, p. 11). From that and follow-up national meetings, CACSL came into being, with the "mothers" of CSL in Canada-Cheryl Rose (University of Guelph, founding Director of CACSL), Sara Dorow (University of Alberta), and Sandra Patterson (Memorial University)_forming the

\footnotetext{
${ }^{1}$ CSL is one of the important ways citizens connect with their post-secondary institutions. In 2012, at the CACSL conference hosted by the University of Saskatchewan, participants decried the lack of materials on Canadian experiences with CSL. I would like to thank Nancy Van Styvendale for her perseverance in bringing this special issue, which gathers such materials, to fruition. Without her encouragement and feedback, my contribution would not have reached completion.

${ }^{2}$ My thanks to Margo Fryer, former chair of CACSL's National Steering Committee and founding Director of UBC Learning Exchange, for providing information about CACSL's history.
} 
first Steering Committee. These women created and can take pride in achieving an amazing movement for CSL in Canada. Their passion led the way.

Part of what this initial committee created was a list of principles for CSL in Canada. Those principles drew me into the world of community-campus engagement. Back in 2009, while I was searching for something else, I stumbled upon the CACSL website. Reading the professed values of CACSL-respect for multiple ways of knowing; a commitment to mutual benefit for all stakeholders; and a belief in shared leadership between community and academic partners-I felt an intense kinship with the CSL community, and from this grew an overwhelming hunger to somehow engage and belong. Given my background in adult learning and career development, I was drawn to the CSL approach. Here, I thought, is an educational philosophy which believes in experiential learning that contributes to society as a whole and acknowledges that everyone should be able to contribute, everyone should benefit, and everyone has something to learn and to teach. Ideas matter; principles matter. I felt I had found a home. I needed to find some way to connect, so I called the CACSL office to inquire about volunteering. Timing is everything. Funding for CACSL had come to an end in $2009,^{3}$ and then-current director Larry Gemmel was leaving to pursue other opportunities. CACSL was at a crucial moment in its history and needed to decide how it would continue to support CSL in Canada. At Larry's suggestion, I made a proposal to the Steering Committee and became the part-time CACSL Director through Interchange Canada. ${ }^{4}$ Full immersion into the world of community-campus partnerships meant a steep and exciting learning curve.

From 2005 to 2009, the J.W. McConnell Family Foundation kick-started the exponential growth and development of CSL in Canada by funding CACSL as well as CSL programs at ten universities. ${ }^{5}$ This created a heyday for CSL, for where there is money, the institutions tend to follow. When I started at CACSL in 2010, the "McConnell Ten," as they were called, had created active CSL programs and a wave of interest in CSL had blossomed across the country. With the end of McConnell funding, I somewhat cynically expected that CSL would slowly fade away without a champion and a funder, but this assumption turned out to be completely inaccurate. While some CSL offices have ceased to exist (University of Sherbrooke), many have continued to support campus and community to engage in CSL (University of Ottawa, University of Alberta): some have reframed themselves to support multiple aspects of community-campus engagement rather than just CSL, and some, like the University of Saskatchewan, have created central points for community to access CSL and other types of CCE (community-campus engagement). Today, in 2017, college and university representatives continue to connect with CACSL to ask about starting CSL programs, and individual faculty members across the

\footnotetext{
${ }^{3}$ In 2004, CACSL "received a 5-year grant from the McConnell Foundation to provide technical advice and support for universities and communities who [were] developing community service-learning programs and to promote the growth of CSL by educating people about CSL and creating national and regional networks of programs, practitioners, and researchers" (Fryer et al., 2007, p. 12).

${ }^{4}$ Interchange Canada facilitates short-term (up to three years) work placements at host organizations, primarily for core public administration employees, to foster knowledge growth/circulation and professional development, among other reasons.

${ }^{5}$ See Kahlke and Taylor, this issue.
} 
country have incorporated CSL into their teaching, sometimes independent of institutional support. Generally, our first piece of advice to post-secondary representatives is to assess what is happening at their institution and to build on the work that is already informally in place.

Certainly, CSL has demonstrated persistence, growth, and value over the past fifteen years. With no additional action, current CSL structures and approaches could well continue to provide opportunities for community and campus to work together to address critical issues. However, in my opinion, without conscious efforts to support community, faculty, and students to engage with each other effectively, CSL will not fulfill its full potential to benefit communities. The remainder of this paper thus explores some principles for enhancing the effectiveness of community-campus engagement, including CSL as one of the key aspects.

\section{What is Community-Campus Engagement (CCE)?}

Both "community" and "campus" have multiple meanings and dimensions. Community can be defined as place-based; virtual; local, national, or international, among other descriptors. Campus can be a set of buildings, an online space, or the site of an outreach activity. Conversations about campus within community can quickly become confusing when we don't start by specifying what we mean by community. In this paper, I am using community in the sense of a physical place.

When we talk about "community-campus partnerships," we often create a sense of dichotomy-community as one entity and campus as another. But my view of campus has always been that it is an integral part of the communities in which it participates. As a prairieraised person who grew up in Saskatoon, Saskatchewan, I saw the university as open and relevant; the concept of town and gown didn't fit my cognitive map. As a child, I saw campus as a place for me, even when I strongly felt the difference between myself and my wealthy schoolmates. However, I understand that this is not the case for everyone, and that my feelings of inclusion are based, in part, on my privileges as a white settler growing up in a family that valued education as a means of escaping poverty.

While post-secondary institutions have often been criticized for being removed from the needs and realities of communities, it is also important to recognize that these institutions participate in community in every action; they are large entities within their communities as well as being nexuses of ideas and action. Any barriers between campus and the rest of community are infinitely porous. As the CACSL website indicates, post-secondary institutions "have a major influence in their community. They can affect the economic and social life of a community by their employment policies, purchasing and investment practices, and their openness to community use of facilities." "But whether or not these institutions can be called "good citizens" of the community depends on the nature of their actions - the way they spend their resources, the way they treat their staff, the way they teach, the way they research,

\footnotetext{
${ }^{6}$ CACSL's website contains a more detailed overview of three elements of campus-community engagement: communityengaged scholarship (which includes CSL, community-based research, co-ops, and internships), community services (which includes extension, advice, media, and speakers), and operations (which includes hiring/purchasing, residences, and building usage).
} 
and the way they connect with others in their community all have a significant impact on the community as a whole. When making decisions, post-secondary institutions need to take into account the impact these decisions have on their communities-but do they?

My vision of effective community-campus engagement is informed by the idea of "anchor institutions," which Dubb and Axelroth Hodges (2012) define as "institutions that consciously and strategically apply their long-term, place-based economic power, in combination with their human and intellectual resources, to better the welfare of the community in which they reside" (as cited in Bartley, 2014). The "anchor institution" perspective promotes the concept that an institution's philosophy and actions contribute to the overall health, wealth, and resiliency of a community. The University of Winnipeg Community Renewal Corporation (UWCRC), for example, demonstrates how a university can focus itself to participate in the social and economic growth and development of its community. A non-profit charitable corporation, UWCRC partners with multiple sectors (community, business, and government) to work on an array of development projects, such as a residence (McFeetors Hall: Great West Life Student Residence), which has both dorms and affordable apartments, half of which are reserved for community members; and a day care, which provides care for children from both the university and wider community.

\section{How Might Community-Campus Engagement be Enhanced?}

\section{Principle 1: Communities Need to Feel Ownership of Community-Campus Partnerships}

By and large, the people talking the most about community-campus engagement are those within the post-secondary system. This focus is understandable, as community engagement constitutes a significant part of the mandate of post-secondary institutions. Community groups and organizations, in contrast, focus on specific goals, issues, or mandates within their communities. If working with a post-secondary institution can help them achieve their goals, excellent. However, given limited resources and ever-increasing needs, community groups and organizations generally do not have the interest or resources to take on the role of improving the larger system that supports CCE. Instead, each develops their own individual mechanisms for working with their local institutions. They may provide feedback directly to the people from campus that they engage with, but by and large, there is no established community voice that advocates to institutional senior management about how the CCE system could work better. $^{7}$ But community voice is essential to community benefit. One recommendation for addressing this deficit is to have a community organization take on the role of communitycampus engagement facilitator, understanding that there are practical and ideological obstacles that might prevent this recommendation from being realistic or even desirable to all community organizations involved. But if such a structure were in place, communities might be able to feel shared ownership of the CCE system.

Another possibility for increasing shared ownership of CCE is to have community-

\footnotetext{
${ }^{7}$ There are, of course, community members at various levels of university governance, but, for the most part, these members are not advocating in a formalized way for improvements to CCE.
}

Engaged Scholar Journal: Community-Engaged Research, Teaching and Learning 
led partnerships, where communities themselves define the relevant issues and strategies, and postsecondary institutions are one among many partners. Every year, multitudes of community-campus projects focus on critical issues such as poverty, violence, food security, diversity, environmental sustainability, and so forth. With a "collective impact," community-led approach, the community would bring together all the organizations dealing with a particular issue, including the post-secondary institutions, and together they would create a strategy for addressing the issue, with each contributing their strengths. ${ }^{8}$ Saint John, New Brunswick, has initiated this type of process through "Living SJ," a multi-sectoral collaboration and collective impact initiative that is working to reduce poverty in the city."

In the absence of community and institutional supports, community organizations can establish mechanisms to make community-campus engagement work for them and their community. An important factor for communities to remember is that the campus needs them sometimes more than they need it. Opportunities for community-based experiential learning and community-based research are often critical to students and professors. Organizations can make the system work for them by taking control of their ability to say "no," or to say "later," or to make clear the processes that need to be followed by those who wish to partner with them. Some organizations establish specific times and ways for institutions to apply to work with them. Others include their partnerships with institutions as part of their business and human resource planning (SAGE Edmonton). Some questions organizations should think about before engaging in CSL are:

- Can projects be created that can be completed in a short period of time and that will support the needs of the community? Most CSL projects will take place over one or two semesters and are usually around thirty hours. What can project participants accomplish in that period of time?

- Is there a larger project that can be modularized so that each part can be taken over by one CSL participant or one group of participants?

- Are there sufficient personnel with the time to develop these projects and to supervise the students? Students are used to doing assignments to be submitted to their professors. Sometimes they forget to keep in contact with the project sponsor about their needs. Most organizations have multiple demands on their time. Consider the cost-benefit of the time spent (i.e. will there be sufficient benefit to make the expenditure of time worthwhile?).

- Are there clear, measurable goals for the project that will enable evaluation?

- To what degree does the organization want to be involved, or to what degree can it be involved, in the design and evaluation of the learning?

- How will students be engaged in learning about the issues at the core of the organization's mandates? How important is this to the organization?

\footnotetext{
${ }^{8}$ This arrangement might be differently envisioned as organic coalitions that involve universities rather than as communityled or community-structured initiatives that formally engage universities. Where these arrangements do exist already, the connection hubs are often social innovation or social action labs that are located in community but that convene crosssectoral collaborators to work on complex social problems.

9 For more on “Living SJ," see Wright (2016).
} 


\section{Principle 2: Post-Secondary Institutions Need to Make the Route to Engagement Clearer and Easier to Navigate for their Communities}

How does a volunteer group of community activists engage with their post-secondary institution? How does a small community organization identify ways in which they could benefit from working in collaboration with their local institution(s)? From the outside, universities are very complex and confusing, making it difficult to know where to start a process of engagement.

A variety of approaches have arisen to address this problem of accessibility. The first approach, discussed briefly above, is to have a stable community organization play a facilitator role. As part of its service to the community, the organization provides support to other community organizations that wish to engage with local institutions. One example is the Trent Centre for Community-Based Education (TCCBE, now the Trent Community Research Centre), which was initially funded by the McConnell Foundation. While the Trent Centre is supported by Trent University, it is an independent facilitator of community-based research, brokering relationships between community organizations and multiple post-secondary institutions. ${ }^{10}$ Another example of a hub organization is the Kitchener Waterloo Volunteer Action Centre, which includes community-campus engagement as part of its services to the community. ${ }^{11}$ These organizations demonstrate the value, for both communities and institutions, of having a stable community-based organization in the role of CCE facilitator, one that is knowledgeable about community as well as the workings of the local institutions: community organizations have someone who can help them connect effectively with their local institution, and institutions are then able to work with community organizations that are more prepared to engage with them. Hub organizations are also able to facilitate collaborative community activity. The positive impact of community-campus engagement would be increased by having more community-based CCE facilitation services to work with college and university centres for engagement. Sadly, finding financial support for such activities is a challenge. A potential role for funders (e.g. government or foundations) would be to provide seed dollars to support existing community organizations such as Volunteer Centres, United Way offices, and Ys to serve as centres for expanding the facilitation of community-campus engagement, perhaps in partnership with university-based units.

A second workable approach to the issue of accessibility, which has already been taken by several institutions to varying levels of success, is the creation of a central institutional point of contact for community engagement. Examples include the Michaëlle Jean Centre for Global and Community Engagement at the University of Ottawa, the Community Service-Learning Office at the University of Alberta, the Community Engagement Service Learning (CESL) Initiative at Red River College, and the University of Saskatchewan's Community Engagement Office at Station 20 West. The first three are located on campus and focus primarily on CSL. The University of Saskatchewan's Community Engagement Office, on the other hand, is located

\footnotetext{
${ }^{10}$ See Kahlke and Taylor, this volume, for more on the TCCBE.

${ }^{11}$ See Hennig, this volume.
} 
within a larger community enterprise centre (Station $20 \mathrm{West}$ ) that provides a wide range of health, employment, and social services to inner city communities; it takes the university to the people. Each of these organizations, in addition to providing service to community, also provides annual reports tracking CCE activity and impact. The existence of an institutional centre is complementary rather than competitive with the existence of a community-based centre. For example, the York University and the United Way have established a strong and effective relationship to support community-based research to the benefit of community organizations and university alike.

\section{Principle 3: Post-Secondary Institutions Need to Ensure Infrastructure to Support Students, Staff, Faculty, and Community Involved in CCE}

All stakeholders — students, staff, faculty, and community—need adequate support to create and sustain collaborative relationships that support healthy, resilient communities. Support infrastructure for community engagement has many facets:

- Administrative support to manage the process and paperwork, facilitate monitoring and evaluation processes, and provide forms and guidelines to be used as models by professors and community partners, at their discretion.

- Training and orientation for students. This training should focus on "soft" skills such as interpersonal communication, good judgement, self-directed learning, and refection skills to assist students in making the most of their CSL experience and contributions.

- Recognition for the increased workload taken on by professors and community organizations to enhance the learning of students and make CSL useful for the community. This recognition can come in many forms. Some institutions provide small grants for community organizations or professors to develop new CSL projects. Others provide teaching release or reduced administrative work for communityengaged professors and researchers. Some have awards for students, faculty, and community organizations to recognize the difference they make, and some are improving recognition for community-engaged teaching and research in the tenure and promotion process.

- Mechanisms to create and support cross-disciplinary CSL programs or courses. Postsecondary institutions, like any large bureaucracy, tend towards multiple silos, which are further entrenched by the nature of academe, where each discipline has its own culture, language, and perspective. Cross-disciplinary CSL can bridge these gaps: it has benefits for students, who learn to value and engage with other disciplines, as well as community organizations, which benefit from a multi- or inter-disciplinary approach to complex issues.

\section{Conclusion}

In conclusion, community service-learning is alive and well in Canada. Individual professors, students, and community representatives are finding ways to make it work and create benefits for society. They experience joy, exhaustion, failure, and success. In today's fast-paced world, 
organizations and institutions alike are over-worked and under-resourced. Despite this, they find ways to make it work. I congratulate all who do this work. You make the world a better place. Thank you.

\section{About the Author}

Geri Briggs, B.Ed., Masters in Continuing Education, joined the Canadian Alliance for Community Service-Learning (CACSL) as Director in 2010 and, beginning in 2012, served as the Co-Manager and Knowledge Mobilization Hub Co-lead of Community First: Impacts of Community Engagement (CFICE).Email: geribriggs@hotmail.com

\section{References}

Bartley, A. (2014, January 14). The rise of the anchor institution: Setting standards for success. The Huffington Post.

CACSL. (n.d.). CSL's role in community-campus engagement.

Fryer, M., Wallis, R., Sattar, K., Annette, J., Battistoni, R., \& Lund-Chaix, A. (2007). Context and culture: Models of engagement around the world. In S. Gelmon \& S. Billig (Eds.), From passion to objectivity: International and cross-disciplinary perspectives on service-learning research (pp. 3-20). Charlotte, NC: Information Age Publishing.

Wright, C. (2016). Sharing successes from Saint John, NB. 